Mark A. Batson MD, Stephen Longmire MD, Eileen Csontos MD

\title{
Alfentanil for urgent Caesarean section in a patient with severe mitral stenosis and pul- monary hypertension
}

We present the case of a parturient with severe mitral stenosis and pulmonary hypertension who received general anaesthesia using alfentanil for urgent Caesarean section. Alfentanil promoted haemodynamic stability and allowed immediate postoperative extubation. Epidural morphine provided postoperative analgesia. This combination permitted early ambulation and prevention of thromboembolism. A disadvantage of this technique, neontal respiratory depression, was promptly reversed with a single dose of naloxone. The anaesthetic management of mitral stenosis in pregnancy is discussed and the neonatal pharmacokinetics of maternally administered alfentanil are presented.

On présente le cas d'une parturiente atteinte d'une sténose mitrale sévère et hypertension pulmonaire avant subi l'anesthésie générale avec de l'alfentanil pour une césarienne d' urgence. L'alfentanil a favorisé la stabilité hémodynamique et a permis une extubation rapide. La morphine en administration épidurale a fourni l'analgésie postopératoire. Cette combinaison a permis une mobilisation précoce et la prévention de l'embolie. Le désavantage de cette technique, la dépression respiratoire néonatale, a été rapidement antagonisé par une dose unique de naloxone. La conduite anesthésique de la grossesse chez les femmes atteintes d'une sténose mitrale est discutée et la pharmacocinétique néonatale et maternelle de l'alfentanil est présentée.

\section{Key words}

ANAESTHESIA: obstetrical, Caesarean section; ANAESTHETICS: intravenous, alfentanil; HEART: mitral stenosis.

From the Department of Anesthesiology, Baylor College of Medicine, Houston, Texas.

Address correspondence to: Dr. M.A. Batson, Department of Anesthesiology, Baylor College of Medicine, One Baylor Plaza - Suite 425-D, Houston, Texas 77030.
Mitral stenosis is the most common of the lethal cardiac lesions occurring in pregnancy, and is present in $0.3-1.2$ per cent of parturients. ${ }^{1,2}$ The maternal mortality is $5-17$ per cent with severe disease, ${ }^{1,2}$ and ranges from $30-50$ per cent when accompanied by pulmonary hypertension. ${ }^{3}$ Although carefully titrated lumbar epidural anaesthesia is often recommended for patients with uncomplicated mitral stenosis, ${ }^{3}$ there is no consensus on the best anaesthetic technique for patients with severe disease. We present a patient with severe mitral stenosis and secondary pulmonary hypertension who required urgent Caesarean section for fetal distress.

\section{Case report}

A 28-yr-old, $165 \mathrm{~cm}, 77 \mathrm{~kg}$, gravida 3, para 2 woman was admitted at 39 wk gestation for amniocentesis to assess fetal lung maturity before elective Caesarean section. Her medical history was significant for gestational diabetes and mitral stenosis. Her surgical history included an uncomplicated mitral commissurotomy 16 mo before this admission, and Caesarean section (for transverse lie) six years earlier under spinal anaesthesia. The postoperative recovery from the Caesarean section was complicated by multiple pulmonary emboli and heart failure.

Maternal echocardiography at the 24th wk of the present gestation revealed marked biatrial enlargement, right ventricular dilation, and an estimated pulmonary arterial systolic pressure of $51 \mathrm{mmHg}$. Trace mitral and tricuspid regurgitation, and mild aortic insufficiency were present. The mitral valve area was $1.1-1.5 \mathrm{~cm}^{2}$. The left ventricular ejection fraction was estimated to be 60 per cent. The patient had no symptoms of heart failure, dysrhythmias, or decreased exercise tolerance during this pregnancy. Her only medication was heparin 5000 u subcutaneously every $12 \mathrm{hr}$, which was discontinued prior to amniocentesis.

Physical examination on admission revealed clear lung fields bilaterally, a nonradiating systolic murmur at the left lower sternal border and apex, and trace pedal oedema without jugular venous distension or hepatomegaly. The 
TABLE Maternal haemodynamic measurements

\begin{tabular}{|c|c|c|c|c|c|c|c|c|c|}
\hline Interval & $\begin{array}{l}H R \\
b p m\end{array}$ & $\begin{array}{l}B P \\
(m m H g)\end{array}$ & $\begin{array}{l}C V P \\
(m m H g)\end{array}$ & $\begin{array}{l}P A P \\
(m m H g)\end{array}$ & $\begin{array}{l}P C W P \\
(m m H g)\end{array}$ & $\begin{array}{l}C O \\
L \cdot \min ^{-1}\end{array}$ & $\begin{array}{l}\text { SVR } \\
\text { dyne } \cdot \mathrm{sec} \cdot \mathrm{cm}^{-5}\end{array}$ & $\begin{array}{l}P V R \\
\text { dyne } \cdot \mathrm{sec} \cdot \mathrm{cm}^{-5}\end{array}$ & $\begin{array}{l}S V R \\
P V R\end{array}$ \\
\hline Pre-op baseline & 74 & $120 / 74$ & 8 & $75 / 35$ & 15 & 5.4 & 1203 & 493 & 2.4 \\
\hline Pre-induction & 94 & $175 / 95$ & 8 & $120 / 55$ & 20 & 5.4 & 1682 & 838 & 2.0 \\
\hline Post-induction & 74 & $106 / 64$ & 8 & $70 / 30$ & NA & 3.5 & 1598 & NA & NA \\
\hline Post-delivery & 75 & $120 / 65$ & 13 & $80 / 35$ & 30 & 7.5 & 749 & 213 & 3.5 \\
\hline Post-op ICU $\left(\mathrm{T}_{0}\right)$ & 87 & $180 / 90$ & 10 & $120 / 55$ & 34 & 6.0 & 1465 & 568 & 2.6 \\
\hline I hr Post-op ICU & 72 & $130 / 70$ & 7 & $80 / 40$ & 19 & 6.1 & 1087 & 450 & 2.4 \\
\hline 24 hr Post-op ICU & 71 & $125 / 69$ & 8 & $81 / 32$ & 19 & 5.4 & 1179 & 434 & 2.7 \\
\hline
\end{tabular}

ECG revealed sinus rhythm, left atrial enlargement, and an RSR $^{\prime}$ pattern in $V_{1}$ consistent with right ventricular hypertrophy. Chest $x$-ray showed cardiomegaly, left atrial enlargement and engorged pulmonary vasculature with cephalization. Haemoglobin, haematocrit, coagulation variables, and serum electrolytes were all within normal limits. Peripheral oxygen saturation was 98-99 per cent while breathing room air.

Amniocentesis resulted in blood tinged amniotic fluid. The $L / S$ ratio was 1.8 , and the $P G$ level was 0.0 , indicative of fetal lung immaturity. Shortly thereafter, persistent abdominal pain and uterine contractions developed, and $\mathrm{MgSO}_{4}$ therapy was begun for tocolysis. Over the next six hours the contractions continued, fetal heart rate beat-to-beat variability decreased, and late decelerations developed. An urgent Caesarean section was scheduled, and the patient was given gentamycin $80 \mathrm{mg} \mathrm{IV}$, ampicillin $1000 \mathrm{mg}$ IV, ranitidine $50 \mathrm{mg} \mathrm{IV}$, metoclopramide $10 \mathrm{mg} I V$, and sodium citrate $30 \mathrm{cc} P O$ prophylactically. Urinary, arterial, and pulmonary arterial catheters were inserted and the patient was taken to surgery.

After preoxygenation and surgical skin preparation, cricoid pressure was applied and a rapid sequence induction performed using intravenous lidocaine $100 \mathrm{mg}$ $\left(1.3 \mathrm{mg} \cdot \mathrm{kg}^{-1}\right)$ alfentanil $10 \mathrm{mg}\left(125 \mu \mathrm{g} \cdot \mathrm{kg}^{-1}\right)$, thiopentone $250 \mathrm{mg}\left(3.25 \mathrm{mg} \cdot \mathrm{kg}^{-1}\right)$ and succinylcholine $100 \mathrm{mg}$ $\left(1.3 \mathrm{mg} \cdot \mathrm{kg}^{-1}\right)$. The trachea was intubated within $90 \mathrm{sec}$. Anaesthesia was maintained throughout the $105 \mathrm{~min}$ using 100 per cent oxygen, enflurane $0-0.5$ per cent, incremental doses of alfentanil (total $16.5 \mathrm{mg}$ ) and an intravenous infusion of succinylcholine for muscle relaxation.

A $3940 \mathrm{~g}$ male was delivered two minutes after induction of anaesthesia. Apgar scores were one at one minute, three at five minutes, and six at ten minutes. Umbilical cord blood obtained at delivery for blood gas analysis revealed venous $\mathrm{pH} 7.16, \mathrm{PCO}_{2} 65 \mathrm{mmHg}, \mathrm{PO}_{2}$ $10 \mathrm{mmHg}$; and arterial $\mathrm{pH} 7.11, \mathrm{PCO}_{2} 63 \mathrm{mmHg}$, and $\mathrm{PO}_{2} 8 \mathrm{mmHg}$. The trachea was intubated and the lungs were ventilated with 100 per cent $\mathrm{O}_{2}$, and he was given naloxone $0.04 \mathrm{mg}$ IM immediately after delivery. Fifteen minutes later the trachea was extubated and he was discharged from the Neonatal ICU after $12 \mathrm{hr}$ of uneventful observation.

Prior to emergence from anaesthesia, the patient was placed in the right lateral decubitus position and epidural morphine, $5 \mathrm{mg}$ in $10 \mathrm{ml}$, was administered at the $\mathrm{L}_{3-4}$ interspace. She was then allowed to awaken, was responsive and comfortable, and the trachea was extubated in the OR. On arrival in the ICU, arterial blood gas analysis showed $\mathrm{pH} 7.40, \mathrm{PCO}_{2} 32 \mathrm{mmHg}, \mathrm{PO}_{2} 247 \mathrm{mmHg}$, and $\mathrm{SaO}_{2} 99$ per cent $\left(\mathrm{FIO}_{2} 0.4\right)$. Eight hours later, arterial blood gas analysis revealed $\mathrm{pH} 7.40, \mathrm{PCO}_{2} 40 \mathrm{mmHg}$, $\mathrm{PO}_{2} 87 \mathrm{mmHg}$, and $\mathrm{SaO}_{2} 97$ per cent $\left(\mathrm{FiO}_{2} 0.21\right)$. A second dose of epidural morphine, $5 \mathrm{mg}$ in $10 \mathrm{ml}$, was given $12 \mathrm{hr}$ later, before the onset of pain or the administration of other analgesics. The patient reported no pruritus or nausea, and her respiratory rate never decreased below $10 \cdot \mathrm{min}^{-1}$. The matemal haemodynamic measurements before, during, and up to $24 \mathrm{hr}$ following Caesarean section are shown in the Table.

Subcutaneous heparin, 5000 u every $12 \mathrm{hr}$, was begun $18 \mathrm{hr}$ postoperatively. The patient required no parenteral pain medications for $30 \mathrm{hr}$, and was out of bed within 18 $\mathrm{hr}$. She was discharged from the hospital with her infant on the fourth postoperative day without further problems.

\section{Discussion}

Patients with mitral stenosis often tolerate the haemodynamic changes of pregnancy poorly. Because of the increases in blood volume and cardiac output associated with pregnancy, symptoms from even mild or moderate mitral stenosis may become severe as the pregnancy progresses. These haemodynamic changes account for a 25 per cent incidence of pulmonary congestion, ${ }^{\prime}$ and a 5-17 per cent mortality rate in the puerperium. ${ }^{1-3}$ The primary anaesthetic considerations in uncomplicated mitral stenosis include prevention of rapid ventricular rates, maintenance of sinus rhythm, avoidance of large, rapid decreases in SVR, and prevention of increases in central blood volume with concomitant increases in PAP. ' To this end, patients usually receive a carefully 
titrated segmental epidural block for labour and vaginal delivery. ${ }^{1-3}$ For Caesarean section, either epidural or general anaesthesia may be used as long as these haemodynamic limitations are considered. ${ }^{1,2}$

In patients with pulmonary hypertension, whether primary or secondary to mitral disease, the peripartum mortality rate is $30-50$ per cent. ${ }^{4,5}$ When patients develop pulmonary hypertension, they also develop right heart strain and become exquisitely sensitive to reductions in preload and to increases in pulmonary vascular resistance. For patients with pulmonary hypertension requiring Caesarean section under general anaesthesia, slow induction of deep anaesthesia using high-dose narcotics or halothane and controlled ventilation seems to be the preferred technique, ${ }^{1,3}$ despite the risk of maternal aspiration.

As this patient had both severe mitral stenosis and pulmonary hypertension, our goal was to provide a stress-free induction of and emergence from anaesthesia, avoiding the increases in heart rate, SVR, and PVR, commonly associated with tracheal intubation and extubation. The need for early ambulation to prevent thromboembolic complications made a technique avoiding postoperative mechanical ventilation while providing profound analgesia of paramount importance. An additional consideration was the need to minimize druginduced neonatal depression.

A carefully titrated epidural anaesthetic would have met these goals. However, the deteriorating fetal condition and subsequent urgency of the Caesarean section precluded this possibility. A variety of techniques including nitroglycerine, nitroprusside, trimethaphan, and betaadrenergic blockade has been proposed to blunt the haemodynamic responses to intubation..$^{7-10}$ Lidocaine, $1.5 \mathrm{mg} \cdot \mathrm{kg}^{-1}$, given as a bolus prior to induction and intubation has also been advocated, ${ }^{12}$ but its efficacy in this situation is unpredictable. ${ }^{13}$ The vasoactive drugs mentioned above may also be useful, but do not provide analgesia, and all have considerable drawbacks such as reflex tachycardia, fetal cyanide toxicity or ileus, tachyphylaxis, or myocardial depression. High-dose fentanyl or sufentanil techniques may provide more haemodynamic stability, but generally require postoperative mechanical ventilation and have prolonged and unpredictable half-lives in newborns which may result in prolonged neonatal depression. ${ }^{4,15}$ Alfentanil offers the haemodynamic advantages of other narcotics, but its short half-life minimizes the need for postoperative ventilatory support and would theoretically avoid prolonged neonatal depression. However, even in high doses, narcotics may be incomplete as the sole induction agent in young, unpremedicated adults. ${ }^{16}$ Therefore, we chose the combination of alfentanil, lidocaine, and a reduced dose of thiopentone to produce a stress-free induction of anaesthesia in this very anxious patient, while avoiding postoperative narcosis and mechanical ventilation.

As shown in the Table, on arrival in the $O R$ the patient's systemic and pulmonary arterial pressures, SVR, PVR, and heart rate were markedly elevated, reflecting her anxiety and pain. Following induction of anaesthesia, these values decreased slightly below baseline, and were accompanied by a modest reduction in cardiac output. Following delivery, PA pressures, CVP, and $C O$ increased without associated increases in heart rate, SVR, or PVR. Therefore, we believed these changes indicated an appropriate response to postdelivery autotransfusion and did not reflect significant ventricular failure. By the end of surgery both SVR and PVR had returned to their baseline values, with little change in the SVR:PVR ratio.

During surgery a low concentration of enflurane was administered to decrease the possibility of matemal awareness, and the cardiovascular effects of such a small amount (0.3 MAC) were negligible. Small, intermittent boluses of alfentanil were administered to provide a stable intraoperative course. The short duration of action of alfentanil allowed awake extubation at the end of the procedure, and may have accounted for the easily reversed neonatal depression.

In addition to the usual risks of postoperative atelectasis and pneumonia, this patient was at extremely high risk for postoperative pulmonary embolism. Therefore, epidural morphine was used to provide prolonged analgesia and allow early ambulation and pulmonary toilet without adverse cardiovascular effects. ${ }^{17,18}$ The gradual but marked decrease in PA pressures over the first postoperative hour may be attributed to the onset of analgesia from the first dose of epidural morphine, and the patient remained pain-free and was out of bed within $18 \mathrm{hr}$ postoperatively.

The biggest disadvantage of this technique was neonatal narcosis. When delivered, the infant was severely depressed and the umbilical cord blood gas analysis revealed evidence of uteroplacental insufficiency. In this case, the degree of depression due to alfentanil is unclear, but it has been shown that while newborns are not adversely affected by low $\left(10 \mu \mathrm{g} \cdot \mathrm{kg}^{-1}\right)$ maternal doses of alfentanil, ${ }^{19}$ at higher doses $\left(35-100 \mu \mathrm{g} \cdot \mathrm{kg}^{-1}\right)$, there can be marked neonatal depression. ${ }^{20-22}$ Despite a low fetal/maternal ratio of 0.29 for total alfentanil, ${ }^{23}$ there is much less protein binding in the neonate $71-73$ per cent) than in the mother ( $85-88$ per cent), and the concentration of free drug is the same in both maternal and neonatal plasma. ${ }^{20.23}$ Equilibrium between maternal and fetal blood is reached in less than ten minutes, ${ }^{23}$ and therefore it appears that placental transfer of alfentanil is both rapid 
and extensive. The elimination of alfentantl in the newborn seems to be slower than in adults, ${ }^{20.23}$ and in one animal model, neonatal plasma levels of alfentanil were actually higher two hours after delivery than they were at birth. ${ }^{23}$ All these factors, and the fact that the infant in our case responded rapidly to naloxone, suggest that alfentanil contributed to the neonate's depression at birth.

The use of alfentanil in general anaesthesia for urgent Caesarean section in a patient with severe mitral stenosis and pulmonary hypertension is presented. This is the first reported case of the use of alfentanil in this situation. It provided cardiovascular stability so that no vasoactive medications were needed. Alfentanil allowed immediate postoperative tracheal extubation, epidural morphine provided excellent postoperative analgesia, and the combination permitted early ambulation and prevention of thromboembolism. A disadvantage of this technique, neonatal respiratory depression, was easily reversed with a single dose of naloxone. Thus, an integrated anaesthetic plan using a short-acting systemic narcotic (alfentanil) intraoperatively, and a long-acting spinal narcotic (epidural morphine) postoperatively facilitated an excellent outcome and early discharge for this severely ill patient and her neonate in a potentially life-threatening situation.

\section{References}

1 Mangano DT. Anesthesia for the pregnant cardiac patient. In: Shnider SM, Levinson G (Eds.). Anesthesia for Obstetrics. Baltimore: Williams \& Wilkins, 1987: 345-82.

2 Ferguson JE, Wyner J, Albright GA, Brodsky JB. Maternal health complications. In: Albright GA, Ferguson JE, Joyce TH, Stevenson DK (Eds.). Anesthesia in Obstetrics: Maternal, Fetal, and Neonatal Aspects. 2nd ed. Boston: Butterworths, 1986: 374-20.

3 Clark SL, Phelan JP, Greenspoon J, Aldahl D, Horenstein $J$. Labor and delivery in the presence of mitral stenosis: central hemodynamic observations. Am J Obstet Gynecol 1985; 152: 984-8.

4 Gleicher N, Midwall J, Hochberger D, Jaffin H. Eisenmenger's syndrome and pregnancy. Obstet Gynecol Surv 1979; 34: 721-41.

5 Jones $A$, Howitt $G$. Eisenmenger syndrome in pregnancy. Br Med J 1965; 1: 1627-31.

6 Abboud TK, Raya J, Noueihed R, Daniel J. Intrathecal morphine for relief of labor pain in a parturient with severe pulmonary hypertension. Anesthesiology 1983; 59 : 477-9.

7 Stoelsing RK. Pharmacology and Physiology in Anesthetic Practice. Philadelphia: Lippincott, 1987: 314.

8 Stoelting RK. Attenuation of blood pressure response to laryngoscopy and tracheal intubation with sodium nitroprusside. Anesth Analg 1979; 58: 116-9.
9 Ferguson JE, Albright GA. Obstetric complications. In: Albright GA, Ferguson JE, Joyce TH, Stevenson DK (Eds.). Anesthesia in Obstetrics: Maternal, Fetal, and Neonatal Aspects. 2nd ed. Boston: Butterworths, 1986: 421-57.

10 Föex $P$. Alpha- and beta-adrenoceptor antagonists. Br J Anaesth 1984; 56: 751-65.

11 Roessler $P$, Lambert TF. Anaesthesia for Caesarean section in the presence of primary pulmonary hypertension. Anaesth Intensive Care 1986; 14: 317-20.

12 Stoelting $R K$. Circulatory changes during direct laryngoscopy and tracheal intubation: influence of duration of laryngoscopy with or without prior lidocaine. Anesthesiology 1977; 47: 381-3.

13 Bartkowski RR, MCDonnell TE. Alfentanil as an anesthetic induction agent - a comparison with thiopentallidocaine. Anesth Analg 1984; 63: 330-4

14 Koehntop DE, Rodman JH, Brundage DM, Hegiland MG, Buckley $J J$. Pharmacokinetics of fentanyl in neonates. Anesth Analg 1986; 65: 227--32.

15 Greeley WJ, de Bruijn NP, Davis DP. Sufentanil pharmacokinetics in pediatric cardiovascular patients. Anesth Analg 1987; 66: 1067-72.

16 McDonnell TE, Bartkowski RR, Williams JJ. ED $\mathrm{ED}_{50}$ of alfentanil in unpremedicated young adults. Anesthesioloy 1984; 60: 136-40.

17 Rosen MA, Hughes SC, Shnider SM et al. Epidural morphine for relief of postoperative pain after cesarean delivery. Anesth Analg 1983; 62: 666-72.

18 Cohen $S E$, Woods WA. The role of epidural morphine in the postcesarean patient: efficacy and effects on bonding. Anesthesiology 1983; 58: 500-4.

19 Dann WL, Hutchinson A, Cartwright DP. Maternal and neonatal responses to alfentanil administered before induction of general anaesthesia for Caesarean section. $\mathrm{Br} \mathrm{J}$ Anaesth 1987; 59: 1392-6.

20 Redfern N, Bower S, Bullock RE, Hull CJ. Alfentanil for Caesarean section complicated by severe aortic stenosis. Br J Anaesth 1987; 59: 1309-12.

21 Golub MS, Eisele JH, Donald JM. Obstetric analgesia and infant outcome in monkeys: neonatal measures after intrapartum exposure to meperidine or alfentanil. Am J Obstet Gynecol 1988; 158: 1219-25.

22 Golub MS, Eisele JH, Kuhneri BR. Disposition of intrapartum narcotic analgesics in monkeys. Anesth Analg 1988; 67: 637-43.

23 Gepts E, Heytens L, Camu F. Pharmacokinetics and placental transfer of intravenous and epidural alfentanil in parturient women. Anesth Analg 1986; 65: 1155-60. 